\title{
MEDICO-LEGAL PROBLEMS IN RELATION TO VENEREAL DISEASE
}

\author{
By F. G. CROOKSHANK, M.D., F.R.C.P.
}

An Address delivered before the Medical Society for the Study of

Venereal Diseases, on Friday, November 27th, I925, at II, Chandos Street.

WHILE I much appreciate the compliment implied in your invitation to me to take part in this discussion, I have to regret the inadequacy of my contribution at the same time that I profess my blamelessness. But, while until a few days ago I understood that my part was to be, very properly, the secondary one of following the lead, or the red herrings, trailed by some legal luminary, yet, in spite of the prodigious exertions of your Secretary, I have found, too late for adequate preparation, that it is my task to initiate debate and to afford material on which others may exercise their quicker wits. Frankly, the time elapsing has been too short for the direction of one's mind in the proper direction. For what are the boundaries of this topic-the medico-legal problems of venereal disease ? Are they not at least as wide as those of medical jurisprudence and toxicology themselves?

May we not say that the practice of your speciality requires and involves acquaintance with all the greater and many of the lesser problems of medical jurisprudence and toxicology?

But, indeed, the medico-legal problems of venereal disease transgress the ordinary limits of medical jurisprudence and toxicology, for they invade the provinces of ethics, of religion, of sociology and of statecraft, and cannot be adequately discussed without some knowledge at least of the humanities and human nature-two subjects necessary for the doctor but not always taught in the schools.

I must therefore place some restrictive interpretation upon my terms of reference and, in the first place, will assume, as well we may, that all doctors here to-night are 


\section{MEDICO-LEGAL PROBLEMS}

fully advised of the actual state of our statutory and common law, and that all lawyers are as fully advised of the difficulties sometimes felt by doctors when medical and legal spheres of interest intersect and interfere without any common axis of rotation.

The problems that we may most profitably discuss are, perhaps, those suggested by some present alleged difficulties in the working of present law, and some others that are brought before our minds by our desire, as medical men, to alleviate social evils by the use of legal machinery.

But, before approaching any of these problems, it may be useful if we attempt to indicate some of the recurrent difficulties that do arise when lawyers and doctors take counsel together, and some of the general principles that may be borne in mind in the endeavour to avoid these difficulties.

Misunderstandings between the two professions seem to me always to arise very simply. On the one hand, medical men are not always willing and anxious to admit that the law is what lawyers say it is. Doctors are oddly anxious to maintain that the law is what they would like it to be, or what they think it should be. Thus, when Jack Jones converts his grandmother into what is called waste material commercially, doctors, if they do not wish him to be hanged, declare that he is insane and therefore must not be hanged. The lawyers, on the other hand, thinking that he should be hanged, and unwilling to admit publicly that according to the law of England an insane person may be hanged, declare roundly that Jack Jones is responsible according to law and, moreover, is not insane, and it is wrong of the doctors to say he is. Of course, each side is wrong. The doctors must recognise that the public has a right to say who should be hanged, while allowing doctors to declare who is insane. The lawyers must allow the public to declare who should not be hanged, and the doctors to say who is insane, while reserving to themselves the function of expressing suitably, and to some extent directing, public opinion. They must not imagine that judge-made law always expresses what is for the best in the best of all possible worlds, and must recognise that the law ultimately derives from public opinion. The doctors, too, must acknowledge at least as much.

Unfortunately we can never get doctors and lawyers to come together and to decide just what is the best way to 


\section{BRITISH JOURNAL OF VENEREAL DISEASES}

carry out the public wishes in the general interest. On the contrary, doctors make up their minds, a priori, who should not be hanged ; lawyers make up their minds who should be hanged; and both sides argue in a circle in support of their own preconceived opinions. Much the same fate attends any medico-legal discussion about venereal disease. Both sides seem to agree, impartially, that at all costs the public interests and public opinion must be disregarded; so the issue is reduced to one of purely professional rivalry!

Let us doctors, then, agree not to dispute the actual position of the law, as did the British Medical Association recently in one of its recurrent and rather ridiculous attempts to impose its temporary view upon the community. And, if we desire to change the law, let us show cause that will appeal to the legislature as conceived in the best interests of the community and the individuals composing it.

But an intrinsic difficulty connected with the discussion of venereal disease in some of its less purely technical relationships arises from the fact that we doctors, though apt to imagine our views based upon the firm rock of experience and observation, do yet pick and choose our facts, and vary our interpretations thereof in accordance with our ingrained prejudices and tendencies.

Just as, according to Coleridge, we are all born into this world either Aristotelians or Platonists, and, according to Gilbert, either Conservatives or Liberals, so are all medical men either followers of Hippocrates or Galen, either Coans or Cnidians. If the latter, we believe disseases to be real entities, endowed with substance and specific qualities, immutable and definitive, and we take the view that venereal diseases are enemies of the human race, differing only from other diseases in that they affect and attack particular organs and so happen to be communicated through and during sexual intercourse. We then see no reason for placing these diseases in any separate pathological, ethical or sociological category, but treat them as natural objects to be destroyed by simple scientific measures, and do not allow the intrusion of any ethical considerations to interfere with our efforts to " abolish" them. But, on the other hand, those of us of an Hippocratic form of mind find in all schematic talk about diseases and their differences and resemblances, and so on, 


\section{MEDICO-LEGAL PROBLEMS}

but mental convenience; and have principal regard, not to the alleged diseases that attack human beings, but to the human beings who are ill in particular ways. Those who think thus come to see that those who are so ill that we say they have venereal disease are either people who behave in a certain kind of way, sexually and ethically, or else those who associate, willingly or involuntarily, with such people.

Such doctors of the Hippocratic school come to see that the kinds of illness we call venereal are correlated with certain kinds of behaviour, and so, even if not regarding these illnesses as the inflicted punishment for sin, do at any rate hold that the ethical rules (if not expressing any law of absolute morality) yet crystallise the experience of countless generations in respect of certain kinds of conduct. Such doctors will not think it possible always to dodge the penalty of the infraction of these rules by making clean the outside of the cup and platter with a $I$ in I,000 solution of mercury. Nor will they hold the difference between vice and virtue to be measured by the tenuity of an indiarubber capsule. My point is, that such differences of opinion in respect of tactics, as till lately divided two great and active societies, depend upon very profound ethical, metaphysical, and pathological tendencies. If these differences can be well composed, medical men can approach the State and the lawyers with greater confidence ; so long, that is, as the differences are reconciled and not compromised.

I confess that, although I would once have ranged myself with the Galenists, the Cnidians, and the realists, I would now (with greater wisdom as I hope, but with more arterial degeneration as my friends say) range myself with the Coan and Hippocratic school. And I would venture to ask, though humbly, whether we have not pushed the nineteenth century doctrines of specificity and of real entities too far ; whether we have not scoffed too cheaply at the notion that disease and diseases may arise de novo (as it used to be said), or at least, whether dirt and impurity may not accentuate virulence and go some way towards converting a harmless saprophyte into a vicious organism that may breed virulently during generations until its own virulence may again attenuate or become dormant? It is again quite clear, I think, that the remedies we may propose, and the legislation for which we may clamour, must be largely determined by our views 


\section{BRITISH JOURNAL OF VENEREAL DISEASES}

in these respects. Those who believe most keenly in the reality and specificity of disease will most ardently cry for specific medical and legal remedies; those who see in venereal disease human reactions that occur in circumstances of dirt, shame, and vice will have the greater faith in procuring observation of an ethical code and the lesser faith in the efficacy of legislation, restrictive, punitive or monitory, or tolerant. Those who think thus will look for the disappearance of venereal disease in accordance with the proper and general observance of a suitable social code of sexual morality-and by suitable I mean one that maintains social stability without imposing too severe a strain upon human nature.

For it is a curious and interesting fact, and one ever to be borne in mind when discussing venereal disease from the point of view of State medicine, that venereal disease, while independent of the nature of the code of sexual conduct anywhere recognised in any place or time, yet does depend upon whether or no that code is generally observed. Apparently when association with prostitutes was compatible with social esteem, as in Greece, in Rome, and amongst the Hebrews, venereal disease was not rife. Prostitution ceases to be dangerous when it is generally recognised as neither shameful nor degrading. As much may be said of promiscuity. In Victorian times, when promiscuity for men and pre-marital intercourse for women (except in the country, where it was harmless quâ disease) was generally thought shameful and against the code, both were dangerous. To-day (as until recently in many parts of Polynesia) pre-marital chastity is no longer expected or desired in the case of respectable young girls. So venereal disease is dying rapidly where fornication is possible without circumstances of shame and secrecy. On the other hand, wherever Christianity has introduced amongst savage races (as we call them) a higher standard of morality (as we call it) - one, that is, that cannot be observed -we have again the paradox that a higher standard of so-called morality implies more disease. I repeat the point, for I believe it to be of fundamental importance. The now rapid diminution of venereal disease is, in my view, not really due to the work of venereal clinics and the like-for in England we never take measures against a danger until the gyroscope of nature has balanced the evil tendency. No ; it is due 


\section{MEDICO-LEGAL PROBLEMS}

to the fact that, rightly or wrongly, an entirely new social code has been set up within the last ten years, one which allows to unmarried women an infinitely greater freedom, and so to men a far greater sexual opportunity, than formerly, and which, in conjunction with other changes in social life-the motor car, the week-end, and so onallows intercourse between the sexes to occur without the attendant circumstances of dirt, drink, shame, and furtiveness, and without entailing social disability. So long, that is, as the new golden rule-that of what is called "playing the game" -is adhered to by both partners. This is a new fact that must affect our whole attitude, and that of the State, towards venereal disease, that we have (almost for the first time for some centuries) a social sexual code that can be observed without undue strain on youthful impetus, and without the tacit setting apart of a class of female hostages for the chastity of other women. But it still remains the fact that venereal disease follows infraction of the new code, and so, although we may no longer regard such disease as an ordained penalty for sin-by sin meaning sexual intercourse outside the blessing and authority of the Church-yet is it impossible for us to divorce its origins from social ethics and to regard it as purely a matter for chemical disinfectants. There is, perhaps, common ground for all if we agree that in the majority of cases venereal disease follows infraction of the social code proper to the particular environment or milieu involved, and that in the minority of cases the so-called innocent sufferer is, as it were, a scapegoat or whipping boy in respect of contravention of the code by another with whom associated.

In my opinion, then, the prevention of venereal disease is, for the individual, a matter of personal conduct or conformity to the prevailing ethical code ; the prevention of venereal disease is, for Society, for the State, a matter best secured by the adoption of a sexual code that allows what may be allowed, and should be allowed, to occur without shame and degradation. In the widest sense it is, for those who think thus, a question of constant adjustment and readjustment in the best interests of the race and of individuals, and not a matter for drastic legislation on the lines of the Medes and Persians. But those who think differently will have different medical and legal remedies to propound. 


\section{BRITISH JOURNAL OF VENEREAL DISEASES}

At any rate, let us remember as much in discussing two or three specific problems.

Since our aim is, without dispute, to prevent the communication of venereal disease to innocent individuals, and to diminish its prevalence in the interests of the State, we have to consider how these ends can be procured without infringement of the ordinary civic and personal rights of the sufferers. Now the very crux of the question is that, however loudly some may say that venereal diseases are just ordinary diseases, no different from others (except in so far as they are commonly communicated by sexual intercourse), nevertheless human nature will not permit us to deal with these diseases by the ordinary processes of notification and sanitary administration. Human nature being what it is, the consequences of breaking the social code will always be considered disgraceful, even though we all break it! And, as I have said, venereal disease is the consequence, or one consequence, of breaking the social sexual code. It is only thus that we can explain why, in the language of an old legal writer, it is actionable to say of any man, "He hath the pox." To say of any man that he has the pox is to suggest that, in effect, he is an antisocial organism; and the damaging effect is in the social avoidance that is brought about by the suggestion.

Now I think we may take it as axiomatic that, however the social sexual code may change, yet the imputation of venereal disease will always be regarded as slanderous and actionable. I venture to say that it will cease to be a matter for damages to say of any unmarried woman that she is not a virgin long before it will cease to be actionable to say of any one that he or she is syphilitic; for to say of an unmarried woman that she is not a virgin will not always, and everywhere, induce social avoidance-in fact it no longer does-while to be poxy is to be shunned, even amongst the most degraded. It is for this reason that any form of legislation that depends for its efficacy upon notifications of venereal disease made by doctors is almost certain to become a dead letter, or to be only exceptionally operative. Just as doctors are ceasing to certify lunatics by reason of the inadequate protection afforded them by the law, so will doctors refuse to notify cases of venereal disease unless formally $r$ rlieved of all responsibility by the law. On the other hand, if the law 


\section{MEDICO-LEGAL PROBLEMS}

does so relieve doctors of the consequences of error and the like, a door will be opened whereby far more serious injury than even that of erroneous certification as a lunatic will be perpetrated; a door, too, which will be open to the blackmailer and to the malignant of either sex.

If there are difficulties, arising from the very nature of the ailment, in the way of securing notification by doctors of venereal disease, there are also difficulties of a professional nature which are bound to arise in any attempt to enforce penalties, in any but the most obvious cases, for the communication, or risked communication, of venereal disease.

I confess that when.I read and hear of the kind of legislation that some women's societies would apparently initiate, and when I think of the shocking fiasco of the Regulation 40D under D.O.R.A., I am appalled at the chaotic state of our medical knowledge when we come down to what are called brass tacks.

I again ask, with all humility and fully aware of the rebukes I may bring upon myself, whether we are all quite convinced, in our inner souls, that the date when the coccus of Neisser, if not the pallid spironema, last became evolved and split off from its compeers, is really so remote that we can be sure that no like evolutionary changes ever occur to-day?

Yet, if it is possible for non-pathogenic strains to become permanently or temporarily pathogenic, under the influence of changes in natural culture media and the like, away go not only a good many doctrines-those of specificity in disease and so on-but much theoretical justification for many proposed medico-legal enactments.

Personally I have often thought that a true gonorrhœea may, and does, develop (in the absence of a truly specific infection) by transmutation, either of the de Vries kind, or gradually by transmission and development through series. And possibly there is something to be said even in respect of syphilis. We cannot explain all the clinical facts by reference to orthodox beliefs. And the hard fact remains that unclean and furtive promiscuity is the fundamental requisite for the appearance of venereal disease, though afterwards specific infection comes into play for at least a series of cases.

Unclean promiscuity will never be suppressed (or greatly v.D. 


\section{BRITISH JOURNAL OF VENEREAL DISEASES}

diminished) unless the sexual needs of a population can be satisfied otherwise than under circumstances that are shameful and dirty. And so it is that legal restrictions and legal encouragements alike of the sale of preventive applications will always be either equally unnecessary or equally futile.

But the point on which I wish to insist is that I do not see how lawyers can draft any Bill which, by making the communication of such disease an offence, will be efficacious in the prevention of venereal disease unless doctors can definitely say, in more than a few cases, that the suspected person must have known himself or herself to have been in an infective condition.

This, it seems to me, reduces the prospects of creating a special offence, in the hope of preventing venereal disease, to a relatively insignificant affair-namely, to that group of cases in which the person accused of having communicated, or attempted to communicate, venereal disease, or of having had connection while suffering and in an infective condition, has been definitely warned by a medical man of his state. But here are fresh difficulties.

Of course if, after due warning, intercourse was performed, with disastrous results, I suppose a lawyer would say that there was the guilty mind that constitutes an action a crime. But it seems to me that the cases in which disease is communicated, apart from prostitution, are, except an insignificant minority, just those cases in which a medical man would have, and does have, most difficulty in swearing that infectivity did exist, or least difficulty in swearing that the accused may have thought himself free from infection. I do not well see how the law can be hoped to restrain in this way many people except those who are already restrained by their own and other people's common sense. Again, any attempt in this country to create a new class of offence must require, as it has done elsewhere, very careful attention to questions of definition and nomenclature that do not appear as yet to have been thoroughly thrashed out. I do not think we can go to the law, even in the interests of the public, before we are very sure of our own ground.

I would remind you, however, that two countries at least, Germany and Sweden, do appear to have adopted during the last few years legislation in respect of the com- 


\section{MEDICO-LEGAL PROBLEMS}

munication of venereal disease, and that their experience must be valuable. So far as I am aware very little of importance has resulted, and very few convictions have been obtained. It would seem as if legislation of this nature rather marks an awakening of public conscience than constitutes a weapon in itself, while there is always the danger that legislation in advance of public opinion and the necessities of the moment may lead to extraordinary and unforeseen consequences, as for prohibition in America. But some reference to the German and Swedish enactments may be made. The German procedure appears only designed to catch what may be called extreme cases of infective persons roaming at large. The Swedish system is more elaborate, if not idealistic. Persons suffering from venereal disease are REQUIRED to consult a doctor, and the doctor, if the patient proposes to marry, MUST inform the Medical Officer of Health, who then communicates with the clergyman of whose congregation the subject is a registered member! And, finally, secrecy is enjoined, though officials are exempted from the obligation of secrecy under circumstances arising during certain kinds of legal proceedings.

In Sweden marriage while suffering from venereal disease is formally prohibited, unless the special consent of the King is obtained, and I believe that now a declaration of freedom is required. This does seem worthy of consideration, though I think its value would be rather by reason of bringing the matter generally forward than by its specific value in special cases.

But clearly, sauce for the goose is sauce for the gander. I do not imagine that any of the few British matrons left would willingly take their young daughters before marriage to a venereal disease specialist for a cervical swabbing, and I rather fancy that if they did the result would be, in some cases, more surprising than satisfactory to the parties concerned.

Moreover, the problems that might, and would result from any whole-hearted application of the provision in question would perhaps be more disastrous than we think. Conceive the consequences of a mistake in judgment! The doctor might be absolved formally by law, but who could compensate the victims of an error ? Our bacteriologists and pathologists have, under force of circumstances, evolved a phraseology that renders their reports harm- 


\section{BRITISH JOURNAL OF VENEREAL DISEASES}

less. What would they not say or do under these circumstances?

The attendant dangers seem to reduce the prospect of advantages from this kind of legislation to almost a nullity.

While, therefore, medical examination before marriage would, in some sense, be ideal if always conscientiously carried out, I cannot help feeling that we could hardly go safely beyond the requisition of a statement on oath, and at the last moment, from either party that there was no known just physical cause or impediment why the marriage should not take place. Such a declaration would go some way towards inducing a feeling of responsibility, especially if it could be arranged that any subsequent revelation of deception should entail some kind of penalty, say, the dissolution of the marriage. But then things are changing so fast that dissolution of marriage is no longer a penalty. It is too often a consummation devoutly to be wished. We seem almost forced to fall back upon a continuance of the present state of affairs, in which we are faced, perhaps not so frequently as is said, but still occasionally, with the fact that, unless we intervene, B., who is infected, will shortly marry C., who is not. This is the favourite case of medical casuists.

The question is thus raised :

Dr. A. is consulted by Major B., who has syphilis. In the course of conversation it appears that Major B. is shortly going to marry Miss C., and refuses to be dissuaded. Dr. A. is a lifelong friend of Miss C.'s father. (In real life syphilitic Major B.'s don't consult the family doctor of their fiancée, or the lifelong friend of her fatherbut let that pass.) A. warns Major B. that he must not marry. B. declares that he will. What is $\mathrm{A}$. to do?

I do not myself feel that any difficulty exists, but I have never come across such a case. It is true that if A. does tell Mr. C., a breach of professional confidence is committed. But who ever said that a medical man should make himself a particeps criminis, as, in such a case, he does if he holds his tongue? Not the oath of Hippocrates. Not the law of England. In some countries the breach of professional confidence is punishable or actionable : in England it is not. We can only be proceeded against for consequences. And what are the conse- 


\section{MEDICO-LEGAL PROBLEMS}

quences in such a case? Is Major B. going to sue Dr. A. for damages, and, if so, is he going to get them ? The case for some indemnification in advance, as has been suggested, seems to me very weak, for were it to be made legal, shall we say, for doctors to communicate information about venereal disease under such circumstances, the only limitations to error, malice, and ignorance would be the limits of human and professional folly. Things must remain as they are. I would say that, as medical men, we must not seek to screen ourselves in advance from the penalty of negligence or error, but in difficult cases should have the courage of our convictions, and be sure that, if we are on solid ground in breaking the shadow of the law and uttering slander or libel, we will not in the long run suffer. Therefore let us always tell our old friend when our best patient has syphilis and is about to marry our friend's innocent daughter. But, as I have said, I think these cases are less rare than it is said.

Still, I have heard of one such in which the parents, though warned, refused to break off the engagement, and the bride is now corrupted and rotten with disease. Well, does not such an event show the hopelessness of providing for all emergencies in advance? For supposing that it were made penal to aid and abet such marriages as this, who initiates the proceedings? The veil of secrecy and shame that surrounds these transactions from the first seems to me to frustrate almost every attempt to attach responsibility in a legal sense to those whom we think guilty. And if ever we do succeed in tearing away this veil of shame and making venereal disease as shameless as tubercle, shall we have benefited the race? After all, which is worse, eugenically: syphilis, or insanity in a bridegroom? You can fight and cure syphilis; can you exorcise insanity with a calomel ointment? But, again, what is Dr. A. to do? Surely his duty is simple. He must warn Major B. and then tell him that if the engagement is not broken off, on suitable grounds, Mr. C. will be told, in the presence of a third party. This seems to me the wise proceeding. I would inform a lawyer (or a parson), and then, in his presence, inform the parent, and if necessary the girl. No action will ever be taken, that is, if $D r . A$. is sure of his facts, and has, if necessary, obtained a second medical opinion. I see no reason for change in the law ; if we once begin there is no end to the inter- 


\section{BRITISH JOURNAL OF VENEREAL DISEASES}

ferences we shall allow. Each man must act as his conscience tells him and stand the consequences.

Medical men are, however, hard to please. While a section clamour for permission to break the FORMAL and quite unwritten seal of confidence when they think fit, others clamour for the right to refuse to do so when the State thinks fit that they should. Now the vast confusion at present existing is the outcome of the wholly ridiculous and thoughtless fuss made several years ago by that rather easily swayed organisation, the B.M.A. In principle, I cannot see how we can safely depart from this, that, doctors being allowed to observe professional confidence in general, from honour, and without penalty if they do break it without malice or accidentally, then they must be prepared to break it under direction of the Courts. Remember: the Courts give us the privilege of bearing witness in court without risk to ourselves; surely we cannot refuse to submit to the rulings of the Courts and to give evidence when required to do so! I have no hesitation in saying that this is the only tolerable arrangement. But I may, and do, recognise that in an exceptional case it may be a high ethical duty to refuse the law's just demand. In such circumstances I must suffer for conscience' sake and be prepared to go to jail for contempt. But I must not make a song about it. I must do what I think right and pay the penalty for so thinking. I do not think that I should suffer very badly.

But, again, there is something more to be said that is of extreme importance, yet which the B.M.A. has refused to consider. I refer to the principle involved in what is known as the Ilford case. Although in the details of this case no question of venereal disease is directly involved, nevertheless the issue is very germane to our present discussion.

Several years ago a girl, living apart from her husband, gave birth to a child whose paternity the husband disavowed. Proceedings were brought against the wife by the husband, and in order to prove this birth the Medical Officer of Health for Ilford, to whom notification of the birth had been made, was called to produce evidence thereof. He protested, but was forced to submit. Now when Lord Mansfield, in the Duchess of Kingston's case, laid down the law that a medical man, who has taken the oath in court, must submit to the direction of the Court 


\section{MEDICO-LEGAL PROBLEMS}

as to the evidence he shall give, medical men were not, as public officers, in possession of information which persons are required by statute to divulge. It appears to me atrocious in the extreme that any person should be forced under penalty to notify to a medical officer of health (by herself or otherwise) details of her private life and that such a medical officer should be forced to divulge them in court, as a result of purely fishing inquiries.

Yet such is the effect of the Ilford proceedings. Here is no question of doctor's privilege or feelings, but something far more important-a question of public right.

Now so long as the procedure in the Ilford case rests unchallenged it is hopeless to expect any notification of venereal disease to be effective. If the State, for official, for its own purposes, forces private persons to divulge, under risk of penalty, information which, if made public, would be prejudicial to their private interests, why at least the State must not allow lawyers acting in opposed private interests to have access to such information. The present case of the venereal disease clinics is otherwise. There attendance is voluntary. What I protest against is compulsion and breach of confidence.

It is strange, however, that there should be, on the part of doctors, a desire to protect the voluntary venereal disease client, but not the mother of an illegitimate infant, who is forced to divulge her secret. It seems to me that the simplest solution is to continue the venereal disease clinics as voluntary institutions, and, so long as they are " voluntary," to make no pledge of secrecy. I have no particular lack of sympathy with venereal disease patients as a rule, but it is clear that if the secrecy rule is made absolute in respect of such institutions, while attendance is voluntary, the offender has free treatment and legal immunity at his command. On the other hand, if we make treatment at venereal disease clinics compulsory I think equity demands that we give security and secrecy to those whom we force to attend, as we should to those whom we force to notify.

I want to make this quite clear. To give absolute or discretionary privilege to officers of venereal disease clinics is to play straight into the hands of the offender and to handicap the man or woman who goes to a private doctor. On the other hand, if the State insists on treating all cases, it must give secrecy or else encourage the clan- 


\section{BRITISH JOURNAL OF VENEREAL DISEASES}

destine and the quack. But, above everything, let us avoid the Ilford pitfall-one of the most important infringements of the liberty of the subject of our time. Do not let us make notification, treatment, or what not, compulsory in respect of venereal disease and then break the confidence, compulsorily acquired, in the interests of any one, blackmailer, wronged husband, or wife.

The right line to adopt seems to me to give all possible assistance to offender and victim alike; to give them the chance, the choice; but not to destroy their sense of responsibility ; and not to make either the way of amendment hard or the way of transgression easy. It is not so much venereal disease as the circumstances productive of venereal disease that, as doctors and citizens, we want to abolish. Laws against sin and vice have always failed for obvious reasons, and will fail again. Sin, vice and disease always flourish when a fictitious morality is set up and human nature is asked to conform to a code with which the average man and woman cannot comply. For when this is done the average man and woman will not condemn the offender, and, as in the play, Measure for Measure is meted out to the law-makers. 